\title{
Influência da relação família-escola na indisciplina
}

A indisciplina está associada ao convívio do indivíduo ao ambiente em que está inserido, que acaba refletindo no espaço escolar, dificultando o trabalho do professor e o andamento das aulas, prejudicando a relação professor-aluno. Por meio de pesquisa bibliográfica, é possível um aprofundamento no tema abordado e uma discussão sobre o papel da família e da escola nos desafios da indisciplina, com o intuito de analisar os benefícios da relação família-escola na educação da criança. Pretendendo-se trazer uma discussão clara sobre o tema abordado, pois, sabe-se que a indisciplina é um tema pouco discutido no âmbito acadêmico, mas na sociedade esse problema é visível e muitas vezes não controlado, dessa maneira pode-se dizer que o trabalho foi de grande relevância, possibilitando refletir na busca de uma educação com parceria familiar no enfrentamento de problemas causados pela indisciplina.

Palavras-chave: Disciplinarização; Disciplina; Instituição; Família.

\section{Influence of the family-school relationship on indiscipline}

Indiscipline is associated with the individual's conviviality with the environment in which he is inserted, which ends up reflecting in the school space, hindering the teacher's work and the progress of classes, harming the teacher-student relationship. Through bibliographic research, it is possible to deepen the theme addressed and a discussion about the role of the family and the school in the challenges of indiscipline, in order to analyze the benefits of the family-school relationship in the education of the child. Intending to bring a clear discussion on the theme addressed, because it is known that indiscipline is a subject little discussed in the academic sphere, but in society this problem is visible and often uncontrolled, thus it can be said that the work was of great relevance, allowing to reflect on the search for an education with family partnership in coping with problems caused by indiscipline.

Keywords: Disciplinarization; Discipline; Institution; Family.

Topic: Bases e Teorias Educacionais

Reviewed anonymously in the process of blind peer.
Received: 24/10/2020

Approved: $25 / 01 / 2021$
Júlio Cesar Ibiapina Neres (iD

Faculdade Guaraí, Brasil

http://lattes.cnpq.br/9493252013144748

http://orcid.org/0000-0002-5277-0790

jcneres@gmail.com

Flávia Carolina Azevedo Maciel (iD)

Faculdade Guaraí, Brasil

http://lattes.cnpq.br/6896023968699001

http://orcid.org/0000-0002-2025-648X

flaviaazevedomaciel@gmail.com

Larissa Leonilda Pereira Melo Vasconcelos

Faculdade Guaraí, Brasil

http://lattes.cnpq.br/3718727871269178

http://orcid.org/0000-0002-6656-3901

larissalpmelo@gmail.com

\author{
Thiago Ibiapina Coelho (iD) \\ Centro de Ensino Unificado de Teresina, Brasi \\ http://lattes.cnpq.br/8986561167505175 \\ http://orcid.org/0000-0001-8405-9015 \\ thiagocoelho.adv@hotmail.com \\ Aluísio Vasconcelos Carvalho \\ Faculdade Guaraí, Brasil \\ http://lattes.cnpq.br/5200758055263996 \\ http://orcid.org/0000-0002-3793-3133 \\ aluisiovasconcelos@gmail.com
}

Referencing this:

NERES, J. C. I.; MACIEL, F. C. A.; VASCONCELOS, L. L. P. M.; COELHO, T. I.; CARVALHO, A. V.. Influência da relação família-escola na indisciplina. Educationis, v.9, n.1, p.1-7, 2021. DOI:

http://doi.org/10.6008/CBPC2318-3047.2021.001.0001 


\section{INTRODUÇÃO}

Cada vez mais os alunos de diferentes instituições de ensino apresentam comportamentos contrários às ações de gestão da sala de aula definidas para uma boa aprendizagem, resultando na indisciplina (DOYLE, 1986). Assim, os comportamentos verbais ou não verbais, capazes de interferir no funcionamento comum da sala de aula são uma das principais preocupações atuais dos docentes, comunidade escolar e dos pais (AIRES, 2010; LANDRUM et al., 2011; SIMÓN et al., 2016).

Nesse contexto, a indisciplina em sala de aula é considerada intolerável por grande parte dos professores, porque gera estresse e esforço extra na gestão da sala de aula, podendo resultar até mesmo na agressividade dos alunos entre si e para com o professor (REYNOLDS et al., 2011).

Dessa forma, os comportamentos inapropriados prejudicam a aprendizagem dos alunos da turma (ROBERS et al., 2012; FERREIRA et al., 2016). E interfere na adaptação dos mesmos no contexto escolar, ocasionando também uma exaustão emocional para professores e alunos (PIWOWAR et al., 2013).

Adiante, vale ressaltar a ambiguidade do termo disciplina, pois ela pode ser interpretada como sinônimo de ordem e submissão, num sentido pejorativo, ou ainda como preceitos e normas a serem seguidas de forma livre e consciente, e a maneira que o aluno interpretar o sentido dessa palavra vai interferir na sua aceitação em segui-la e consequentemente na sua conduta na escola (SILVA et al., 2016).

Por outro lado, muitas vezes a justificativa do aluno possuir falhas morais que o torna indisciplinado é associada à postura do professor e à comunidade escolar, quando na verdade, a família é a primeira parte responsável pela educação da criança, sendo ela que deve ensinar valores e princípios (AQUINO, 1998).

Diante disso, o presente artigo tem como objetivo investigar as causas da indisciplina na sala de aula e discutir o papel da família juntamente com a comunidade escolar para coibir esse problema desafiador, pois as regras, condutas e disciplina são necessárias para uma boa convivência em sociedade, tratando-se da sala de aula, essa disciplinarização torna-se ainda mais urgente pois relaciona-se ao processo de aprendizagem do aluno. E suas práticas transpassam o espaço escolar, relacionando-se também ao âmbito familiar, uma vez que a família é o alicerce no desenvolvimento do indivíduo e tem a responsabilidade de educá-lo, enquanto a escola tem apenas o papel de ensiná-lo competências e habilidades.

\section{METODOLOGIA}

Trata-se de uma sistemática revisão de literatura, com caráter qualitativo, resultante da busca bibliográfica ampla e diversificada em bases eletrônicas, periódicos e portais como: CAPES, Scielo e outros, com autores atuais em torno de 10 anos, e clássicos. Para seleção do material foram inseridas nas guias de busca as seguintes palavras-chave: Disciplinarização, Disciplina, Indisciplina, Instituição e Família. Além disso, foi realizada uma análise crítica para escolha dos artigos, dissertações e teses que melhor representassem os objetivos desta pesquisa. 


\section{DISCUSSÃO TEÓRICA}

\section{Afinal, o que é disciplina?}

O termo disciplina remete a ideia de ordem, obediência às regras, e a mesma vem da palavra discípulo (aquele que segue), entende-se assim que a disciplina está ligada com o ato de aprender (SILVA et al., 2016).

Michel Foucault (1999) foi um dos pensadores que se dedicou a analisar os elementos que constituem os componentes da disciplinarização. Em seu livro "Vigiar e punir", o autor compara muitas vezes a escola com entidades disciplinadoras e rigorosas, como as prisões e quarteis, devido suas exigências autoritárias como: a uniformização, regras, filas e dentre outras.

Assim para o autor Foucault, a disciplinarização escolar começa a ser organizada no século XVIII através da disposição dos alunos em fileiras seja na sala de aula, corredor ou pátio escolar, determinação de metas a serem atingidas através de cada prova, cada semana, mês ou ano letivo, a ordem dos conteúdos e a divisão dos alunos por faixa etária (BORELLI et al., 2017).

Dessa forma, para Foucault (1999) essas exigências constantes de regras no âmbito escolar servem como intuito de controlar os alunos, sendo considerado um ato de disciplinarização, pois, através do mesmo, os tornam fáceis de manipulação e dessa maneira a disciplina no ambiente escolar facilita a observação dos alunos para deslocamento e estabilidade em determinados ambientes, seja dentro ou fora da escola.

As regras e leis são disciplinas criadas para organizar, regularizar, penalizar e outros, existindo para um desempenho da sociedade. Essa associação entre a disciplina e o homem faz parte da sua rotina, pois os cidadãos estão em meio à sociedade como se fossem sentinelas e vigiadores, sempre observando o comportamento um do outro, seja para condenar, analisar ou até mesmo punir (BORELLI et al., 2017).

Em sala de aula essa relação está sendo moldada de acordo com a evolução e modificação da ideia de poder, e o que mantem a disciplina nos anos atuais é o bom convívio entre professor/aluno facilitando o ato ensinar, que antes era traçado pelas punições e castigos que atualmente são proibidos. Atualmente o aluno é participante ativo da aula e as metodologias de ensino tornaram-se mais voltadas para a formação integral do aluno e menos para o tradicionalismo rígido e autoritário,

Jesus et al. (2010) ressalta que na Abordagem Tradicional a disciplinarização no "ato pedagógico é centrado na palavra [...], desta forma, o ensino só acontecerá se o aluno se mantivera "calado, quieto, atento, obediente e respeitado [...]". Desta forma é possível que muitas escolas ainda trabalhem com uma abordagem tradicional, onde o aluno deve ouvir, ficar calado e consentir o desejo do professor, que tem por objetivo disciplinar os alunos e só depois transmitir conhecimento, porém esse tipo de abordagem passa a ser ultrapassada e a disciplinarização na sala de aula atual deve ser voltada para uma convivência pacífica e respeitosa, sem que isso seja imposto com autoritarismo, colocando o aluno lado a lado do professor e não como seu submisso (SILVA et al., 2016).

A Escola Tradicional considera que os alunos ouçam as regras que a eles foram impostas e que a disciplina seja adquirida sem questionamentos, de forma consentida. No entanto, Jesus et al. (2010) defende a aplicação da disciplina consentida ao invés da disciplina imposta, pois assim o aluno irá compreender e 
aderir voluntariamente às regras do ambiente escolar e não se sentirá obrigado a obedecer, apenas.

Nesse sentido, a Escola Nova declara que a disciplina deve ser concebida de forma democrática, onde as regras e deveres propostos pela instituição atuem como auxílio da autonomia do aluno, uma vez que a autonomia é essencial para a aprendizagem, e quando a disciplina não é duramente imposta, a instituição oferece uma oportunidade de construção das relações na sala de aula sem conflitos e dão aos alunos a chance de auto avaliarem suas condutas (JESUS et al., 2010).

Dessa forma, para que a disciplina aconteça é importante que haja interação entre o docente e o discente, para que aconteça uma construção e participação ativa tanto para um quanto para o outro, sabendo lidar com as diferenças (SILVA et al., 2016).

\section{Indisciplina: causas e consequências para a aprendizagem}

Segundo Hagenauer et al. (2015) e Lopes (2006) a indisciplina na sala de aula é caracterizada por atitudes como: deixar de realizar uma atividade proposta pelo professor, fazer uso de termos de baixo calão, insultar e desrespeitar os colegas e o professor, fazer os colegas perderem o foco da aula e darem mais atenção á brincadeiras e outras formas de interromper a aula. Tais comportamentos contrários ao padrão são chamados de off-task (fora da tarefa) (NASH, 2016).

Indagações envolvendo indisciplina vêm crescendo muito, sendo um obstáculo mundial que não ocorre somente na escola, sempre está associada à regras e normas impostas pela sociedade, relacionadas às características diferentes que cruzam a escola, até mesmo do professor, dos fatos do ambiente familiar, que muitas vezes estão se tornando menos rígido e menos autoritário, contribuindo para o crescimento da indisciplina, estando associada com os fatores internos e externos, que devem ser analisada pelos aspectos familiares, sociais, cognitivo e etc. (SIQUEIRA, 2017).

Desta forma, na visão de Jesus et al. (2010) a indisciplina "tem assumido ao longo dos tempos diferentes significações: punição; dor; instrumento de punição; direção moral; regra de conduta para fazer reinar a ordem numa coletividade; obediência a essa regra", esses conceitos apresentam formas decorrentes das práticas adotadas pelas escolas, na intenção de adequar o bom funcionamento e relacionamento entre professor-aluno, favorecendo assim, a aprendizagem.

As práticas teórico-metodológicas utilizadas sobre indisciplina, mantêm heranças culturais e traços do passado, por isso é importante analisar quais condutas a escola pode adotar para que essa indisciplina não venha ocorrer, pois, na atualidade em que vivemos a indisciplina vem se agravando nas escolas e na família, tal problema que muitas vezes não conseguem solucionar (SIQUEIRA, 2017; JESUS et al., 2010).

Muitos motivos podem levar o filho ou o aluno a não se comportar de maneira adequada, sabe-se que ninguém nasce indisciplinado, a criança descobre como agir a cada dia, a forma com que os pais educam seus filhos é uma das influências de disciplina ou indisciplina (JESUS et al., 2010).

Jesus et al. (2010) consideram que "os atos de indisciplina que ocorrem no ambiente escolar são decorrentes da interação entre a escola e o meio social e da própria violência da sociedade, ou seja, muitos dos atos de indisciplina que ocorrem no ambiente escolar são, para a autora, reflexos do momento histórico 
e das ações da própria sociedade". É a partir do convívio que o indivíduo adquire seu comportamento, sabendo que ninguém nasce indisciplinado.

Assim uma autora alega que o comportamento indisciplinado é resultante de influências recebidas e internalizadas, tendo os responsáveis pela criança grande interferência nesse processo, e os fatores influenciadores podem ser externos: a violência social, ambiente familiar mal estruturado, conflitos psicológicos; ou internos: o relacionamento mantido entre o professor e o aluno, e se esse convívio não for prazeroso, poderá despertar no aluno um mau comportamento.

Conforme afirma Lopes (2006), os fatores determinantes da indisciplina podem ser ainda escolares (perfil de ensino adotado e funcionamento organizacional), do professor (didática, características pessoais e profissionais, experiência e capacidade de administração da sala de aula) e familiar.

E nessa visão Siqueira (2017) classifica a indisciplina como privado e público, referindo-se às relações de afeto e às relações de trabalho ou coletividade, respectivamente. Distinguindo que a indisciplina está relacionada com o público e o privado, portanto o privado é a vida e a ligação familiar, e o público é a vivência social, e o convívio da cidadania em meio a tantas regras e princípios. Se o indivíduo não for preparado, quando Ihe faltam estabelecimento de regras na sociedade em que vive, não saberá distinguir o que é certo e o que é errado, achando correto praticar comportamentos indisciplinados.

À vista de tais argumentos, torna-se visível que a indisciplina contribui negativamente para a aprendizagem tanto de quem pratica os atos fora das atividades propostas quanto para quem tem sua atenção desviada por outros durante a aula (FERREIRA et al., 2016).

\section{Papel da família x papel da escola no processo de disciplinarização}

A família é a primeira instituição no processo de desenvolvimento da criança, e é definida como um grupo de pessoas com ligações afetivas que se tornam o berço de ensinamentos de um indivíduo, não necessariamente precisa ter um pai e uma mãe ou terem uma relação sanguínea. E como na escola estão matriculadas crianças de diferentes famílias, estas também são diferentes, podendo a criança ter recebido uma boa formação familiar ou ter enfrentando situações difíceis e negativas, resultando numa grande diversidade (SIQUEIRA, 2017).

Adiante, a instituição escolar é um ambiente especializado para oferecer oportunidades educacionais para a garantia da educação básica de qualidade para todos, devendo oferecer aos alunos conhecimentos aplicáveis na sua realidade, presente e futura, preparando-os para serem inseridos na vida social e no mercado de trabalho (SILVA, 2014).

No entanto, algumas pesquisas alegam que em escolas particulares o índice de indisciplina é menor quando comparado às escolas públicas, tal fator está intimamente ligado à estrutura familiar (LEBLANC et al., 2007). Além disso, Rothstein et al. (1999), ao estudarem sobre as principais diferenças entre escolas públicas e privadas, notaram que as decisões administrativas da instituição privada e suas políticas são mais claras e menos propensas a conflitos, porque existe uma homogeneidade maior entre os familiares e responsáveis, que sabendo das regras institucionais não responsabilizam os professores ou agentes 
administrativos pelo comportamento dos filhos.

Além do mais, num estudo realizado na Espanha por Kyriacou et al. (2010), visando compreender a visão dos educadores sobre os comportamentos indisciplinados, a maioria dos participantes da pesquisa disseram que o maior problema era o fato dos alunos não esperarem sua hora de falar, e a principal justificativa desses comportamentos continuarem se repetindo é a falta de parceria dos pais para transmitir valores às crianças quando elas estão fora da escola. Os mesmos autores afirmam que os professores passam mais tempo corrigindo os comportamentos dos alunos do que deveriam, e isso prejudica o tempo da aula.

Assim, a família tem também uma função social sobre a criança e ao adolescente, além do dever de garantir provimento para realizarem atividades promissoras e uma educação moral dentro dos valores da sociedade em que estão inseridos (OLIVEIRA, 2002).

\section{CONCLUSÕES}

O presente artigo possibilitou uma visão ampla sobre disciplina, disciplinarização e indisciplina, contribuindo para uma análise do índice de indisciplina em sala de aula ao longo dos anos. Foi possível observar que esse problema é crescente e tem resultado em grandes problemas no ambiente familiar e escolar, principalmente no processo de aprendizagem e desgaste dos professores, que dificilmente conseguem conduzir suas aulas sem serem interrompidos por comportamentos inadequados dos alunos.

As causas desta indisciplina são várias, envolvendo a escola e a família, pois ambas são o local de convívio da criança e do adolescente. No entanto, muitas atitudes identificadas como inapropriadas para a sala de aula estão mais relacionadas aos bons modos e valores, do que à didática e profissionalismo, portanto, existe um desencontro entre o que a escola propõe e o que a família permite que a criança e ao adolescente fazem, de modo que os hábitos são levados da casa para a escola. Mas, em muitos casos a família não se responsabiliza pelas suas obrigações, atribuindo à comunidade escolar tarefas que não a pertencem.

Quanto ao verdadeiro papel do professor deveria ser de conduzir, ensinar, transmitir conhecimento e instigar o desenvolvimento crítico, preparando os alunos para viverem em sociedade, mas essa função tornou-se distorcida de tal modo que são vistos como amigo, psicólogo, e até mesmo como pais dos alunos, dando afeto e educação.

Dessa maneira, torna-se necessário que as famílias reconheçam sua função educativa, retirem da escola a missão de transmitir os valores e bons modos que não fazem parte das exigências do cargo ao qual se propuseram a ocupar. Além disso, sugere-se que a escola deve ter regras e normas consistentes e bem definidas, mas não autoritárias, mesmo que seja da rede pública, e estas devem ser de conhecimento de todos os funcionários, dos pais e responsáveis e dos alunos, para que possam juntos construir um convívio agradável e favorável à aprendizagem. Também é necessário que a escola juntamente com a família possa realizar projetos para solucionar essa problemática.

Por fim, espera-se que essa pesquisa sirva de inspiração à novos trabalhos da mesma temática, e que a escola seja um local de transformação de comportamentos, tanto para os profissionais que precisam estar preparados para enfrentar os desafios, quanto para os alunos que necessitam agir de forma responsável, 
consciente e independente frente às diversas situações cotidianas.

\section{REFERÊNCIAS}

AIRES, L.. Disciplina na sala de aulas: um guia de boas práticas para professores do 3ㅇcciclo do Ensino Básico e Ensino Secundário. Lisboa: Edições Sílabo, 2010.

AQUINO, J. G.. A indisciplina e a escola atual. Rev. Fac. Educ., São Paulo, v.24, n.2, p.181-204, 1998. DOI: http://dx.doi.org/10.1590/S0102-25551998000200011

BORELLI, A. C. S. B.; PELEGRINI, T.. O conceito de (in) disciplina, e disciplinarização no âmbito escolar. In: CONPEF - CONGRESSO NORTE PARAENSE DE EDUCAÇÃO FÍSICA ESCOLAR, 8. Anais. Londrina: Universidade Estadual de Londrina, 2017.

DOYLE, W.. Classroom organization and management. In: WITTROCK, M. C.. Handbook of research on teaching. 3 ed. New York: Macmillan, 1986. p.392-431.

FERREIRA, A. C.; SANTOS, E. R.; ROSSO, A. J.. Representação social da indisciplina escolar. Psicologia: Teoria e Pesquisa, v.32, n.1, p.199-208, 2016. DOI: https://doi.org/10.1590/0102-37722016012074199208

HAGENAUER, G.; HASCHER, T.; VOLET, S.. Teacher emotions in the classroom: Associations with students' engagement, classroom discipline and the interpersonal teacher-student relationship. European Journal of Psychology of Education, v.30, n.4, p.385-403, 2015. DOI: https://doi.org/10.1007/s10212-015-0250-0.

JESUS, G.; MAIA, G. Z.. Indisciplina escolar: reflexões. Revista de Iniciação Científica da FFC, v.10, n.1, 2010.

KYRIACOU, C.; MARTIN, J. L. O.. Beginning secondaryschool teachers' perceptions of pupil misbehavior in Spain. Teacher development, v.14, n.4, p.415-426, 2010, DOI: https://doi.org/10.1080/13664530.2010.533481

LANDRUM, T. J.; LINGO, A. S.; SCOTT, T. M.. Classroom misbehavior is predictable and preventable. Phi Delta Kappan, v.93, n.2, p.30-34, 2011. DOI: https://doi.org/10.1177/003172171109300207

LEBLANC, L.; SWISHER, R.; VITARO, F.; TREMBLAY, R. E.. School social climate and teachers' perceptions of classroom behavior problems: A 10 year longitudinal and multilevel study. Social Psychology of Education, v.10, n.4, p.429-442, 2007. DOI: https://doi.org/10.1007/s11218-007-9027-x

LOPES, E. M. B. L.. Indisciplina em contexto educativo. Dissertação (Mestrado em Activação do Desenvolvimento Psicológico) - Universidade de Aveiro, Aveiro, 2006.
NASH, P.; SCHLÖSSER, A.; SCARR, T.. Teachers' perceptions of disruptive behaviour in schools: a psychological perspective. Emotional and Behavioural Difficulties, v.21, n.2, p.167-180, 2016. DOI: https://doi.org/10.1080/13632752.2015.1054670.

OLIVEIRA, L. C. F.. Escola e família numa rede de (des)encontros: um estudo das representações de pais e professores. São Paulo: Cabral, 2002.

PIWOWAR, V.; THIEL, F.; OPHARDT, D.. Training inservice teachers' competencies in classroom management. A quasiexperimental study with teachers of secondary schools. Teaching and Teacher Education, v.30, p.1-12, 2013. DOI: https://doi.org/10.1016/j.tate.2012.09.007

REYNOLDS, K.; STEPHENSON, J.; BEAMAN, R.. Teacher perceptions of non-compliance in rural primary schools in New South Wales. Education in Rural Australia, v.21, n.2, p.105, 2011.

ROBERS, S.; ZHANG, J.; TRUMAN, J.. Indicators of School Crime and Safety: 2011. NCES 2012-002/NCJ 236021. National center for education statistics, 2012.

ROTHSTEIN, R.; CARNOY, M.; BENVENISTE, L.. Can Public Schools Learn from Private Schools? Case Studies in the Public \& Private Nonprofit Sectors. Washington: Economic Policy Institute, 1999.

SILVA, D. A. G.. A Indisciplina: Causas e consequências no processo do ensinar e aprender. Monografia (Especialização em Coordenação Pedagógica) - Universidade Federal do Paraná, Curitiba, 2014.

SILVA, E. R.; ABUD, M. J. M.. As representações docentes sobre as causas da indisciplina na escola: De quem é a culpa? Revista do GEL, v.13, n.1, p.87-106, 2016. DOI:

https://doi.org/10.21165/gel.v13i1.548

SIMÓN, C.; ALONSO-TAPIA, J.. Positive classroom management: Effects of disruption management climate on behaviour and satisfaction with teacher. Revista de Psicodidáctica, v.21, n.1, p.65-86, 2016.

SIQUEIRA, M. S. C.. Indisciplina escolar: contribuições da família e da gestão escolar. Dissertação (Mestrado em Educação) - Escola Superior de Educação Almeida Garrett, Lisboa, 2017.

A CBPC - Companhia Brasileira de Produção Científica (CNPJ: 11.221.422/0001-03) detém os direitos materiais desta publicação. Os direitos referem-se à publicação do trabalho em qualquer parte do mundo, incluindo os direitos às renovações, expansões e disseminações da contribuição, bem como outros direitos subsidiários. Todos os trabalhos publicados eletronicamente poderão posteriormente ser publicados em coletâneas impressas sob coordenação da Sustenere Publishing, da Companhia Brasileira de Produção Científica e seus parceiros autorizados. Os (as) autores (as) preservam os direitos autorais, mas não têm permissão para a publicação da contribuição em outro meio, impresso ou digital, em português ou em tradução. 